\title{
IMPORTAÇÕES DE ÂNFORAS DE AZEITE NA BRETANHA ROMANA: 20 ANOS DEPOIS*
}

Cèsar Carreras Monfort ${ }^{1}$

\section{Resumo}

Pedro Paulo A. Funari realizou pesquisas em anforologia na Bretanha romana no final da década de 1980 e início da década de 1990. Ele estava interessado na epigrafia (inscrições pintadas e selos) da ânfora mais comum nas ilhas, que era a Dressel 20 bética. Seu conhecimento supunha uma mudança importante na forma como as ânforas foram estudadas no Reino Unido e influenciaram os estudiosos e pesquisas posteriores. $\mathrm{O}$ presente trabalho tenta mostrar a sua contribuição na pesquisa de ânforas na Bretanha romana e como esses estudos evoluíram nos últimos 20 anos. Claro, existem novos dados disponíveis, mas também abordagens alternativas em termos de metodologia e interpretação.

\section{Palavras-chave}

Arqueologia das ânforas romanas; Bretanha romana; Pedro Paulo Funari.

\footnotetext{
* Texto traduzido do inglês por Lorena Pantaleão da Silva, doutoranda em História, UFPR.

${ }^{1}$ Profesor Titular, Universitat Autònoma de Barcelona, Barcelona, España. E-mail: cesar.carreras@uab.cat
} 


\begin{abstract}
Pedro Pablo A. Funari carried out research in amphora studies in Roman Britain in the late 1980s and early 1990s. He was interested in the epigraphy (painted inscriptions and stamps) on the most common amphora in the Isles, which was the Baetican Dressel 20. His scholarship supposed an important change in the way amphorae were studied in the United Kingdom and influenced later scholars and research. The present paper attempts to overview his contribution in amphora research in Roman Britain, and how those studies have evolved in the last 20 years. Of course, there are new data available, but also alternative approaches in terms of methodology and interpretation.
\end{abstract}

\title{
Keywords
}

Archaeology of Roman amphorae; Roman Britain; Pedro Paulo Abreu Funari. 


\section{Introdução : Pesquisa nos anos 1990}

Talvez as pessoas não saibam que Pedro Paulo A. Funari dedicou parte da sua carreira no final dos anos 1980 e 1990 ao estudo das importações de azeite de oliva na Bretanha Romana. Interessado em particular na epigrafia presente nas ânforas Béticas classificadas como Dressel 20, o que incluía os selos e as inscrições pintadas (tituli picti). Ele peregrinou por diversos museus britânicos documentando essas inscrições presentes em coleções para as quais ninguém havia destinado maior atenção desde o trabalho de M.H. Callender (1965).

O seu detalhado estudo das coleções de alguns museus resultou na publicação do livro "Dressel 20 inscriptions from Britain and the consumption of Spanish olive oil: with a catalogue of stamps" em 1996. Seu trabalho tornou evidente desde o início a importância do consumo de azeite de oliva na Bretanha Romana, uma vez que as ânforas Dressel 20 são os recipientes mais comuns em qualquer coleção na província durante o Principado. Ademais, ele selecionou uma série de sítios romanos (Londres, St. Albans, Colchester, Vindolanda e Caerwent) para comparar as inscrições registradas, suas origens e datações. Uma de suas contribuições mais originais foi a abordagem semiótica no estudo das inscrições, comparando tamanhos em relação às medidas romanas, assim como os tipos das letras.

A pesquisa de Pedro Paulo gerou um novo interesse no estudo de ânforas pelos estudiosos Britânicos, que organizaram com a sua colaboração uma Conferência no Museu de Londres chamada Ânforas na Bretanha e o Império Ocidental, em 1993, cujas comunicações foram publicadas dez anos depois no Journal of Roman Pottery Studies (volume 10, em 2003). Anteriormente, apenas o trabalho de Williams e Peacock (1983) tinha fornecido uma visão geral sobre as importações de azeite de oliva na Bretanha Romana. 


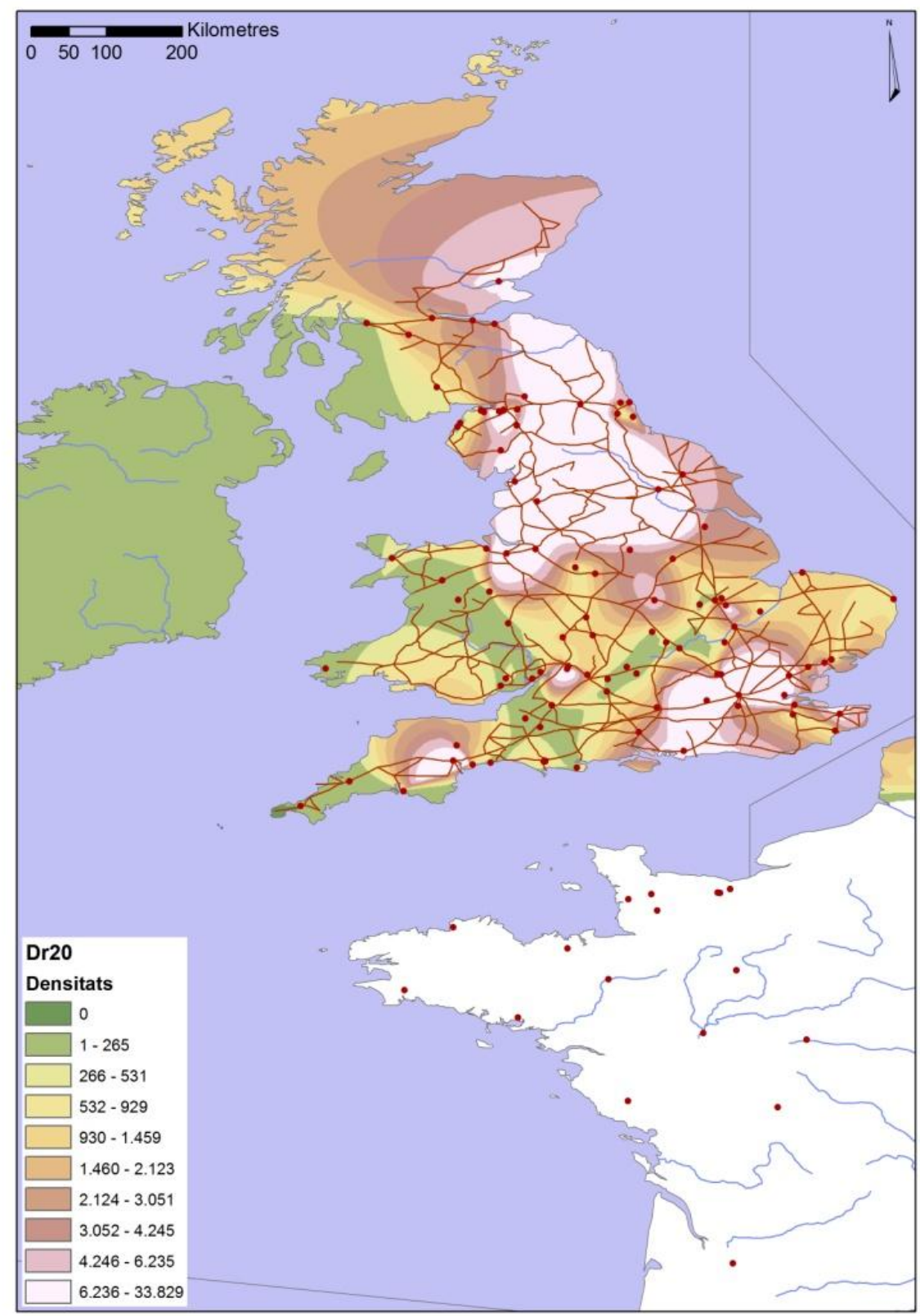

Fig.1. Distribuição Densitária das ânforas Dressel 20 (cg/m2)

Eu tive o prazer de conhecê-lo na Universidade de Southampton onde eu estava concluindo meu doutorado também acerca das aforas provenientes da Bretanha Romana, mas utilizando métodos diferentes e estudando todos os modelos de ânforas. Nós decidimos colaborar mutuamente auxiliando um ao outro em temas como epigrafia, coleções museológicas e escolha de amostras no intuito de evitar esforços duplicados. Ao fim, nós decidimos publicar juntos um livro sobre a importação de azeite de oliva na Bretanha Romana em 1998 com o título Britannia y el Mediterráneo: estudios sobre el abastecimento de aceite bético y africano en Britannia (Brittannia e o Mediterrâneo: estudos sobre 
o abastecimento de azeite bético e africano na Brittannia) com um catálogo completo de selos de ânforas.

Este novo trabalho ampliou o número de ânforas de azeite de oliva documentadas, incluindo modelos como a Dressel 23 Bética tardia e os vasos norte africanos (Williams e Carreras, 1995), ao lado da célebre Dressel 20 Bética. Apesar do fato de a ânfora Dressel 20 continuar sendo o vaso mais comumente registrado em qualquer coleção de ânforas na Bretanha Romana desde o período Claudiano até o século III d.C., havia mudanças nos sítios, regiões e cronologias que demandavam uma resposta mais precisa.

Uma visão geral da Distribuição das ânforas Dressel 20 (Figura 1), de acordo com a densidade de uma amostra de 109 sítios (marcados na figura 1), revelou uma alta concentração do consumo desta ânfora na área militar no entorno do muro de Adriano, nas principais cidades da província (Londres e Colchester) assim como no condado de Devon (basicamente Exeter). Considerando que esta tipologia representava em peso cerca de 60 - 70 \% da maioria das coleções de ânforas na Bretanha, sua distribuição total deveria identificar a o padrão geral de consumo de azeite de oliva (veja imagem 1). Os outros receptáculos de azeite de oliva menos presentes não afetavam essa distribuição uma vez que a Dressel 23 foi apenas encontrada, naquela época, em Winchester; ao passo que ânforas norte africanas eram apenas conhecidas em poucos locais e em baixa densidade.

Ademais, uma série de mapas com a distribuição de selos de Dressel 20 provenientes de diferentes períodos cronológicos claramente identificaram os movimentos do exército romano em cada fase (Carreras e Funari, 1998, figuras 28-32). Desse modo, era evidente que o consumo de azeite de oliva da Dressel 20 estava relacionado a destacamentos militares, talvez uma parte do chamado annonamilitaris. Este sistema esteve em funcionamento até uma clara desaceleração na importação do azeite de oliva ao final do século III d.C., quando os recrutas do exército romano foram basicamente adquiridos em meio à população local.

Por que o estado romano criou um sistema tão complexo e dispendioso para suprir com azeite de oliva seu exército em diferentes limes ? A possível resposta não é simples, mas está na crença de que o azeite de oliva era considerado um item básico na dieta dos legionários. Um tipo de gordura mediterrânea substituída por manteiga ou banha pelas populações de territórios ao norte; em outras palavras, um tipo de alimentação étnica que os soldados romanos não poderiam viver sem. 
Longe da fronteira, outra concentração de população mediterrânea na Bretanha estava no sudeste onde havia também uma alta densidade populacional, outra variável que pode ter afetado a distribuição das Dressel 20. Naturalmente, nem todos os potenciais consumidores de azeite de oliva eram de origem Mediterrânea, uma vez que a Dressel 20 aparece por toda parte mesmo em sítios rurais ao sul da Bretanha. Uma população local romanizada pode também ter consumido azeite de oliva, mas em menor quantidade e pagando mais caro. Assim sendo, o poder de compra também se concentrava ao sudeste da Bretanha e era outra variável para compreender a distribuição das Dressel 20.

Finalmente, tentamos esboçar os custos de transporte no interior da Bretanha Romana digitalizando as infraestruturas de transporte e aplicando a análise de rede GIS (ARC/INFO) (Carreras, 2000). Os mapas resultantes identificaram a maioria das distribuições das outras ânforas com exceção da ânfora Dressel 20, pois esta parece ser resultado de um sistema público de redistribuição que não considerava os custos de alocação. No entanto, estes mapas demonstraram custos mais baixos nas costas Sudoeste ou Sudeste dependendo das rotas marítimas dos carregamentos de ânforas .

Estas conclusões foram elaboradas naquela época baseadas em uma quase completa coleção de selos anfóricos e titula picti, e uma amostra quantificada de 109 sítios incluindo as principais cidades romano-bretãs e a maioria dos territórios. A questão é, estas conclusões continuam válidas após 20 anos?

\section{Novas evidências das Dressel 20, Dressel 23 e das ânforas norte africanas: 20 anos depois.}

Naturalmente, a amostragem de 1990 era sempre incompleta para algumas das cidades mais populosas como Londres ou Colchester, e existiam também muitas cidades menores sem nenhum exemplar, assim como territórios com pouca representatividade como o Muro Antonino, Gales e o sul da Escócia.

Nos últimos anos, ocorreram mais escavações e mais relatórios foram publicados, aumentando a amostragem inicial de ânforas, contudo as tendências iniciais parecem ter se mantido inalteradas. As ânforas Dressel 20 continuam sendo o recipiente mais comum nas coleções de ânforas durante o Principado, alcançando porcentagens entre $50-60 \%$ do total. Quando isso não ocorre, os relatórios indicam que se trata de uma coleção 
incomum na qual normalmente a Gauloise 4 excede em número as Dressel 20. Existem mais exemplos de ânforas Dressel 23 tardias em locais como Londres e Dorchester e muito mais ânforas norte africanas em locais específicos em contextos tardios.

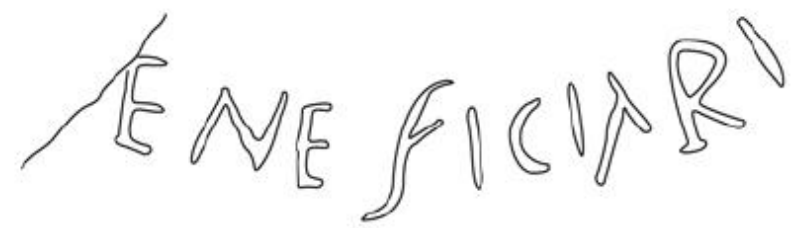

Fig. 2. Grafite de um fragmento do corpo de uma Dressel 20 proveniente de Vindolanda (Inv. 9311) (Marlière e Torres, 2005, 223-226)

As descobertas mais memoráveis são provenientes de Vindolanda (Chesterholm), onde mais de 42 novos selos foram desenterrados desde 1996. Marlière e Torres (2005) publicaram as ânforas recuperadas entre 2003 e 2004, as quais incluíam 19 selos novos e relatos de ânforas de diferentes períodos cronológicos. De acordo com os autores, a coleção continha 120 Dressel 20 de um total de 140 ânforas quantificadas pelo MNI. Ânforas Dressel 20 eram predominantes em todos os períodos de 85 d.C. até 350 d.C. A presença de destroços de barris nestas escavações acarretou a possibilidade de comparar o volume do conteúdo de diferentes receptáculos tais como barris e ânforas. As conclusões esboçadas sugerem que vinho ou cerveja e não azeite de oliva possam ter sido o principal produto importado no local, caso barris de madeira sejam considerados como principais recipientes de transporte (Marlière e Torres, 2005).

Finalmente, o mesmo artigo inclui um grafittum de uma Dressel 20 escrito B]ENEFICIARI (figura 2). No sítio de Vindolanda, há evidencias de beneficiarii em uma inscrição em pedra do século II (AE 1940, 0108; RIB1696) e de três tábuas de madeira datadas entre 97 e 120 d.C. (Tab. Vindolanda II, 180; 344; III, 643). Beneficiarii eram cargos especiais no exército romano responsáveis por garantir o abastecimento e também por atuar como policiamento(Carreras, 1997). Desta forma, eles podem ter sido responsáveis pelo controle do abastecimento de azeite de oliva, entre outras mercadorias, para o forte de Vindolanda.

Mas Vindolanda também forneceu novas descobertas, quando SheehanFinn (2012) publicou 23 novos selos das escavações de 2007-2012, alcançando o número total de 123, número que provavelmente aumentou com os esforços dos últimos anos. Um estudo cuidadoso do contexto de 
datação de onde todos esses selos de Dressel 20 são provenientes confirma um fornecimento constante de azeite de oliva Bético desde 90 d.C. até 270 d.C. Os selos restantes aparecem em um contexto posterior mas como material residual.

\begin{tabular}{|lll|}
\hline Período & Selos/ano & Selos \\
I (c. 75-90 d.C.) & 0 & 0 \\
II (c. 90-100 d.C.) & 0.1 & 1 \\
III (c. 100-105 d.C.) & 1 & 5 \\
IV (c. 105-120 d.C.) & 0.8 & 12 \\
V (c. 120-140 d.C.) & 0.65 & 13 \\
VI (c. 140-213 d.C.) & 0.5 & 41 \\
VII (c. 213-270 d.C.) & 0.56 & 32 \\
VIII (c. 270-360 d.C.) & 0.01 & 1 \\
IX (c. 360-400 d.C.) & 0.05 & 2 \\
X (post 400 d.C.) & 0.06 & 3 \\
u/s & & 9 \\
unknown & & 4 \\
\hline
\end{tabular}

Fig. 3. Selos de ânforas Dressel 20 de Vindolanda por período (após Sheehan-Finn 2012)

É interessante frisar que Vindolanda foi sempre ocupada por tropas auxiliares, não legionários e desde 213 d.C. pelos IV Cohors Gallorum Equitata. Estes auxiliares poderiam não ser de origem Mediterrânea, mas consumiam azeite, assim como qualquer membro do exército romano.

Os novos dados de Vindolanda confirmam a esmagadora importância da Dressel 20 e das importações de azeite de oliva na zona militar ao norte. Escavações recentes em Dixon Lane Junction e na George Street em York (Williams, 2015) também combinam a predominância das ânforas Dressel 20 juntamente com a Gauloise 4, assim com a alta representação da Dressel 2-4 da Campânia e 9 fragmentos de ânforas norte africanas sem forma definida. Novamente, York registra o mesmo tipo de coleção de ânforas típicas dos acampamentos militares do norte com a adição de vasilhas norte africanas que podem ter chegado em um período posterior.

Na parte ocidental do país, próximo a Gales, existem novos dados de Wroxeter provenientes do recente livro acerca da escavação dos sítios na cidade de Worcester (Evans e Williams, 2014), que registram os mesmos modelos de ânforas (Dressel 20, Gauloise 4 e Dressel 2-4 da Campânia). Não obstante a baixa densidade da ânfora Dressel $20(17 \mathrm{cg} / \mathrm{m} 2)$, que é comum nessa região, as vasilhas Béticas representam em peso $87 \%$ da coleção. 
Talvez Londres seja o local onde mais pesquisa se faz necessária para atualizar os dados sobre ânforas devido ao tamanho da antiga cidade e as numerosas escavações de salvamento. Apenas algumas das publicações disponíveis apresentam a relevância da importação de Dressel 20 para a capital, tais como a escavação do cemitério de Mucking (Williams, 2013), com uma alta proporção deste modelo de ânfora, assim como um selo onde se lê LIT registrado.

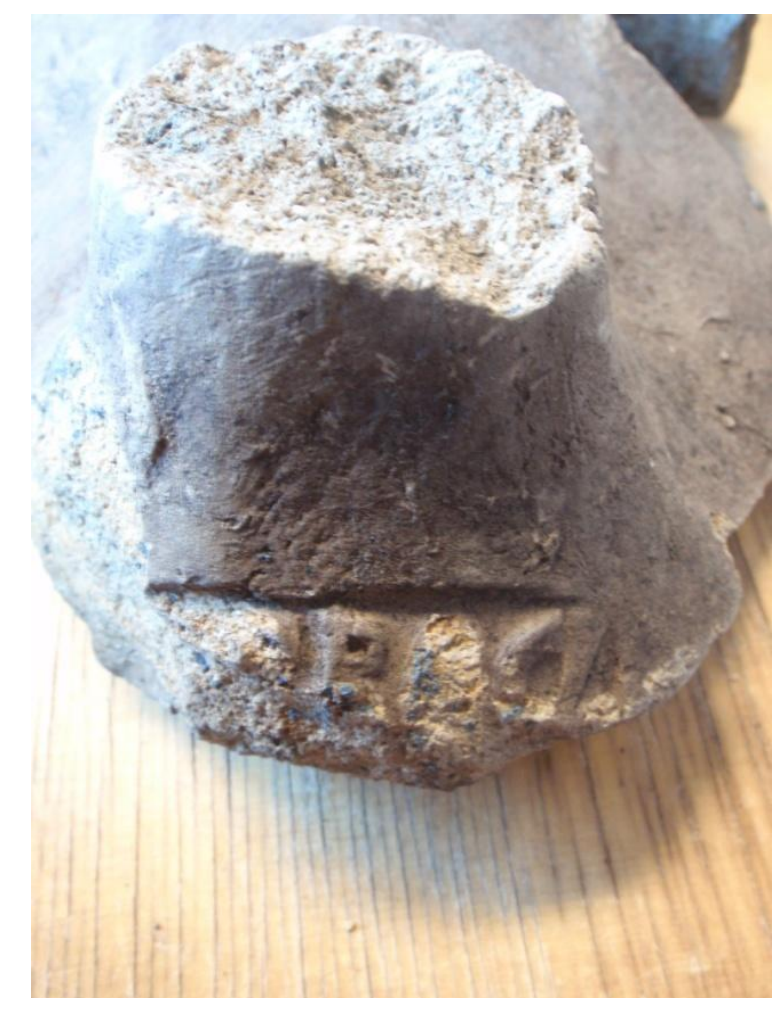

Fig. 4. Selo Dressel 20 de Moorgate in radiceansae (London, MOLAS INV.7842) (Cortesia de D.F. Williams)

Porém, há mais selos de Dressel 20 surgindo nas expedições de salvamento que ainda não foram devidamente publicados. Alguns deles parecem até ser famílias de selos como é o caso de um proveniente de Moorgate (Molas, Inv. 7842) (figura 4). O estado do selo da Dressel 20 não permite uma leitura clara exceto as duas últimas letras que identificam um CI, enquanto dois caracteres incompletos podem indicar as letras A e P. A base de dados de Selos do CEIPAC (http://ceipac.ub.edu/) não fornece nenhuma correspondência e os selos mais próximos são $o$ CPCI ou PONTICI. A única correspondência provém do selo APICI na Dressel 6B, cuja fabricação não corresponde a da amostra de Moorgate e que normalmente aparece no aro e não sob a alça.

Todavia, a possibilidade de novas descobertas nas escavações em Londres vem do relatório da Bow Bells House (Howell, 2013), onde há a 
esmagadora presença de Dressel 20 e Gauloise 4, mas também 31 exemplares da London 555, Dressel 2-4 e ânforas exóticas como a Dressel 28, Benghazi MR-1 e outro exemplar da Dressel 23. Londinium, como uma grande capital da província com uma população multicultural, fornece um modelo mais completo e diferenciado de importação de ânforas do que qualquer outra região da Bretanha Romana. Ela merece um estudo sistemático e completamente quantificado dos selos e tituli picti, assim como a reunião das ânforas por período, o que pode iluminar algumas formas específicas de consumo.

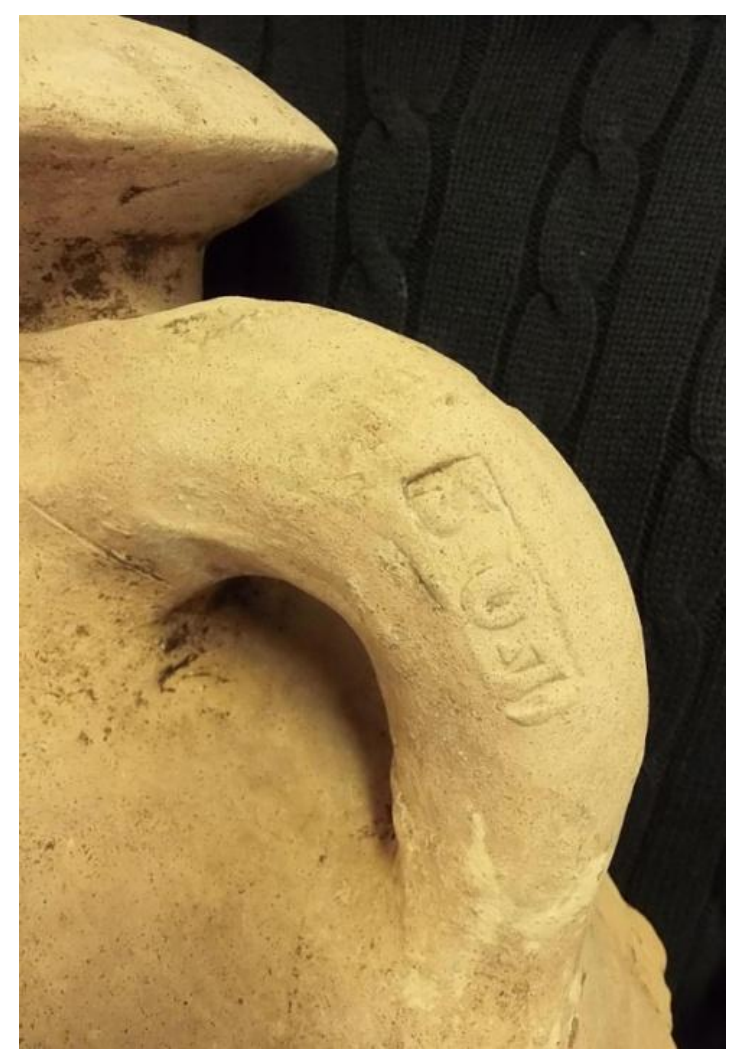

Fig. 5. Novo selo LQS em uma Dressel 20 proveniente de St. Helens (Colchester)

Finalmente, a região sudoeste fornece informações interessantes sobre as ânforas Dorchester (Smith, 2008: 4-5), com uma esmagadora presença de Dressel 20 e Gauloise 4, o que confirma as tendências gerais de 20 anos atrás. O relatório também reforça os números de selos Dressel 20 com um LQS e outro ilegível. Além disso, também demonstra que a quantidade de ânforas Gauloise 4 excederam as Dressel 20 em alguns períodos, e que existem também evidências de outras ânforas de azeite de oliva tais como a Dressel 23 e vasilhas norte africanas (8 fragmentos datados entre os séculos III e IV d.C.).

Este breve sumário de publicações relevantes sobre ânforas nos últimos 20 anos apresenta novas descobertas e o grande potencial dos dados mais recentes. No entanto, até onde sabemos as linhas gerais acerca do Heródoto, Unifesp, Guarulhos, v. 3, n. 1, Março, 2018. p.288-312 
fornecimento de azeite de oliva na província se mantém inalteradas após estes 20 anos, com algumas correções secundárias. Naturalmente, completar a coleção de selos (figura 5) e inscrições pintadas, assim como uma sólida amostra de ânforas ao longo da bretanha romana, reforçará esta visão geral.

\section{Revisitando antigas interpretações sobre o consumo de azeite de oliva}

Apesar de os novos dados não afetarem as linhas gerais da importação de azeite de oliva, interpretações antigas são sujeitas a questionamento. Evan (2013) descreve com detalhes as mudanças nos hábitos de consumo de azeite de oliva na Bretanha Romana, destacando o maior consumo em áreas militares e no sudeste da Bretanha, e apontando que o o consumo do azeite dificilmente adentra em sítios rurais ao sul e quase nada ao norte. Assim sendo, a população local e humilde provavelmente não consumia o azeite importado.

Com a ruptura do fornecimento militar de Dressel 20 no final do século III d.C. o consumo geral de azeite na província diminuiu. Ela argumenta que o exército romano, constituído pela população local do século III em diante, não demandava tal despesa. Todo o comércio interprovincial entrou em colapso mas ainda havia elos comerciais com as províncias mediterrâneas, como demonstra a presença da Dressel 23 e das ânforas norte africanas. Além disso, a rede comercial interprovincial e as rotas em direção às regiões militares continuavam fortes, como revela a distribuição de cerâmica de fabricação local a partir do século III.

Estas distribuições dos artefatos locais de cerâmica do século III nos lembram os modelos de simulação de custos do transporte criados em GIS para explicar a distribuição de ânforas (Carreras, 2000). Elas identificaram claramente como ocorreram estas distribuições de cerâmica com exceção da Dressel 20 (figura1). O simulador de transporte para a Bretanha romana foi atualizado em 2013 (Carreras e De Soto, 2013) com um software superior (ARC/GIs) e com um novo algoritmo (Kernel Analysis), fornecendo assim uma compreensão mais precisa nos fatores de alocação.

A figura 6 mostra o resultado da simulação de Exeter (esquerda) e Porchester (direita) como dois locais de passagem essenciais do Canal Inglês por onde as ânforas possivelmente chegavam. Existem outros mapas começando em Dover ou Colchester que identificam claramente o assim chamado comércio da costa oriental (Evans, 2013), ao passo que os 
dois ilustrados na figura 6 podem identificar o comércio da costa ocidental.

Caso a distribuição da ânfora Dressel 20 não possa ser identificada em nenhum destes mapas provavelmente se deve a intervenção estatal que alterou o efeito do custo dos transportes, e os mapas de Exeter e Prochester podem se encaixar na distribuição de outras ânforas menos comuns.
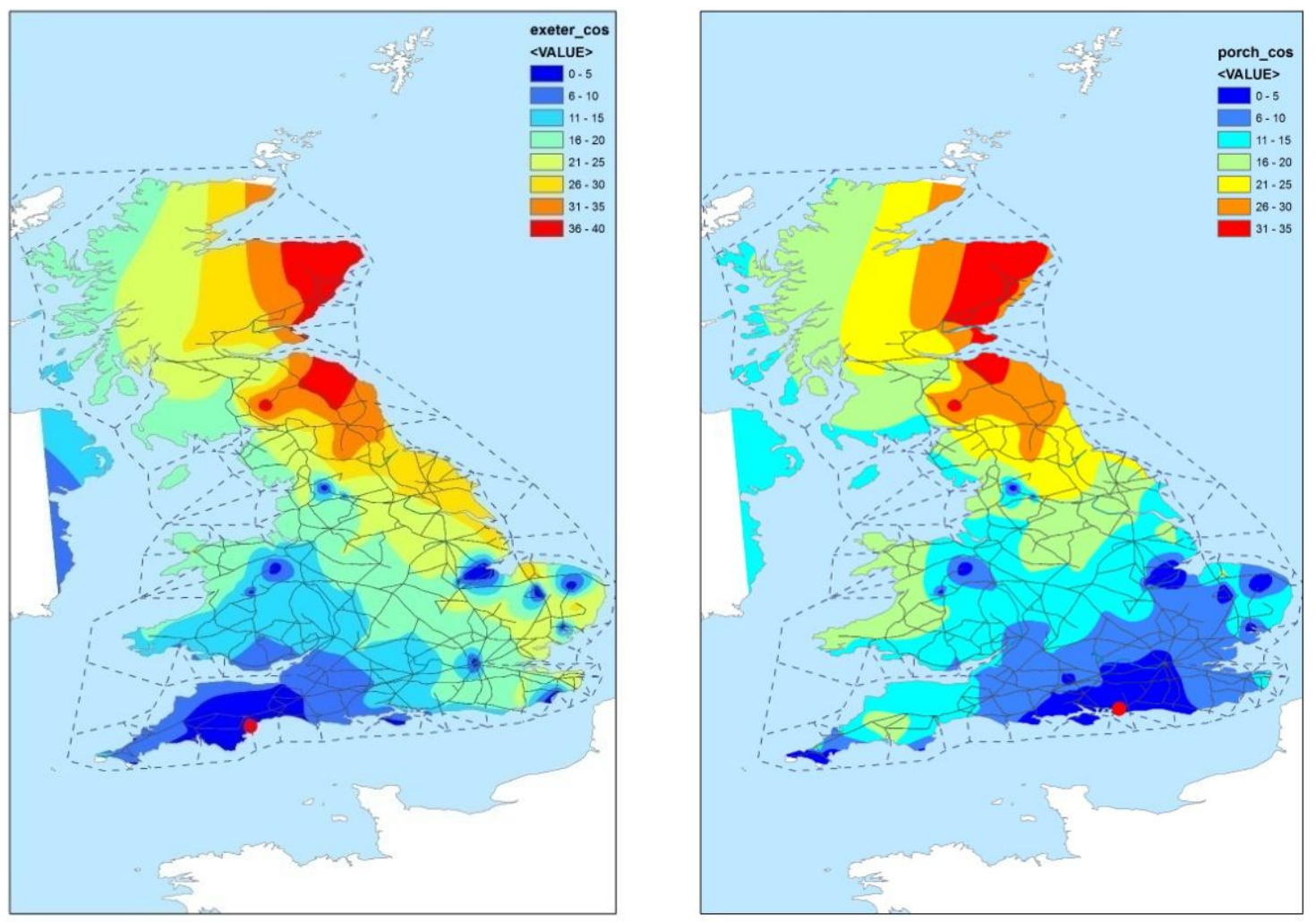

Fig. 6. Simulação dos custos de transporte em ARC/GIS Exeter (esquerda) e Porchester (direita) (Carreras e De Soto, 2013)

Como citamos anteriormente, o número de sítios com Dressel 23 aumentou em ao menos 3 cidades (Winchester, Londres, Dorchester), ainda que em quantidades muito pequenas. Apesar da necessidade de mais dados quantificados, a atual distribuição de Dressel 23 parece identificar uma distribuição ao sul, talvez mais próxima do mapa simulado de Prochester.

No que se refere as ânforas no norte africano², as evidências são maiores e mais dispersas apesar de elas nunca terem se equiparado às importações iniciais dos vasos Dressel 20. Atualmente existem evidências de ânforas

\footnotetext{
2 Nem todos os vasos norte africanos continham azeite de oliva; pelo contrário, alguns deles transportavam produtos como molho de peixe. Assim, é importante considerar este aspecto.
} 
norte africanas em York, Exeter, Londres, Leicester, Lincoln, Colchester, Winchester, Mucking (Londres), Dorchester (Dorset), Mothecombe (Devon), Bantham (Devon), Springhead (Kent) e no castelo de Tintagel (Cornualha). A maioria das evidências destas ânforas aparecem ao sul e, sobretudo, na costa sudoeste, com exceção dos aquartalamentos das Legiões militares de York, ao norte. A distribuição no sudoeste coincide com as rotas de comércio daquela região (Evans 2013) e a localização de outros produtos do mediterrâneo oriental, tais como ânforas foceences de verniz vermelho e ânforas romanas tardias, também documentadas na Irlanda (Kelly, 2010). Esta concentração nos portos do sudoeste sugere que o caminho pelo atlântico era a rota mais provável em direção às ilhas britânicas a partir do Mediterrâneo (Carreras e Morais, 2012).

O uso da análise cruzada para a interpretação arqueológica aumentou na última década com o desenvolvimento de softwares e as suas aplicações sociais. No que se refere à Bretanha romana, existem dois trabalhos brilhantes que analisam a distribuição de plantas exóticas nas ilhas britânicas (Livarda e Orengo, 2015; Orengo e Livarda, 2016). O primeiro trabalho aborda a distribuição destas plantas exóticas vindo de outras províncias e latitudes no interior da cidade de Londinium (Londres), empregando análise SNA, a qual desenvolve o algoritmo de grau de centralidade (concentração de consumo) e centralidade intermediária (centros de redistribuição) (Livarda e Orengo, 2015). Ambos os conceitos indentificam os consumidores primários e possíveis mercados de distribuição na Londres romana, os quais podem apontar outras variáveis como grupos étnicos, poder de compra e mercados ou revendedores especializados. Os trabalhos analisam estes diferentes padrões de distribuição para cada período cronológico que apresenta alguma mudança.

O segundo trabalho analisa a distribuição destas plantas exóticas encontradas em toda a província da Bretanha romana, empregando os mesmos conceitos e software (Orengo e Livarda, 2016). Este segundo estudo de caso reforça a importância das conexões terrestres e introduz a LCR (the least cost route) para explicar o grau de centralidade e centralidade intermediária . No que se refere à concentração de consumo (grau de centralidade), existem altas concentrações em Londres, Midlands e York (assim como em outros centros militares menores como Newstead, Carlisle, Ribchester e Castleford). No entanto, uma distribuição militar geral não é encontrada, nem uma população mediterrânea, mas uma possível combinação de preferências alimentares e poder de compra parece refletir esta distribuição, ainda que seja difícil de demonstrar. 
Padrão de consumo é um tema desafiador que foi pouco trabalhado pela literatura especializada. Swan (1992) tentou relacionar a presença de novos grupos de cerâmica (Ebor ware), que lembravam a forma de produtos de culinária norte africanos (caçarolas) na York romana tardia, com a chegada de imigrantes africanos. Ela relacionou essas evidências cerâmicas com as campanhas de Septimus Severus (208-211 d.C.) ao norte da Bretanha, nas quais Ebucarum (York) era o quartel general (Legio VI Victrix). Ela argumentou que a cerâmica norte africana chegou junto com aquelas tropas à cidade de York. A evidência de imigrantes africanos é escassa e baseada em inscrições tais como a do liberto mouro, em South Shields (RIB 1064; - 160-180 d.C.), ou Numerous Maurorum Aurelionarum, em Burgh-by-Sands (RIB 2042 - 253-8 d.C.), assim como esqueletos humanos com traços negróides no cemitério de Thentholme Drive (York). Ademais, ela argumenta que Constante e Constantino também incentivaram a imigração africana em direção a York.

A senhora com bracelete de marfim (Leach et alii, 2010) é uma das tumbas do cemitério de Thentholme Drive que foi identificada como possivelmente uma mulher africana. O sepulcro consiste em uma caixa de pedra e uma série de bens, dentre as quais destacam-se os objetos de marfim. Além disso, as medidas do crânio feminino (craniometria) tendem a identificá-la como uma possível migrante africana.

As importações de um grande número de ânforas norte africanas para a York romana, que também foram documentadas nos últimos 20 anos, dão maior base para esta hipótese.

O atual e o futuro desenvolvimento de análises de DNA em cemitérios romanos na Bretanha irão iluminar a questão da real composição da população romano-bretã e a relativa importância dos imigrantes. Estas análises de DNA que começam a dar resultados relevantes em locais como Londres podem embasar um indicador de consumo de alimentos específicos, como é o caso do azeite de oliva e das plantas exóticas.

Até agora, acadêmicos que estudam o consumo de alimentos na bretanha romana (Alcock, 2001; Cool, 2006) descrevem os vestígios alimentares e as possíveis estratégias dietéticas sem elaborar uma distinção entre as diferentes populações. Romanização é o ambíguo termo que justifica a adoção de novos ingredientes, mas quantidade e preferencias tendem a variar de acordo com a população de origem.

Por exemplo, Cool $(2006,63)$ destaca as mudanças que o fim do sistema de redistribuição pública (no século III d. C.) em York acarretou no consumo. Ela acredita que o azeite era relevante na cozinha, mas não 
mais necessário quando a maioria dos recrutas do exército da província passou a vir da própria bretanha. Ela ilustra a utilização do azeite de oliva na cozinha com uma única análise lipídica de uma patina em Chelmsford com restos de azeite de oliva e ovos, um dos primeiros casos de ovos fritos documentados (Cool, 2006, 64). Finalmente, ela relembra que o consumo de plantas exóticas (i.e. especiarias) é bem documentado em espaços militares (tabuleta de Vindolanda 184).

Pode-se concluir com uma reflexão final sobre a concentração de ânforas norte africanas no sudoeste da Bretanha. Novas descobertas confirmam um consumo relevante de azeite de oliva africano nesta região, que não parece refletir nenhuma identidade alimentar específica (Jarrett, 2010). Pelo contrário, a chegada das ânforas norte africanas junto com outros produtos do mediterrâneo oriental (ânfora romana tardia, foceense de verniz vermelho) reforça a ideia de que a distribuição está relacionada a rotas marítimas particulares e transporte costeiro associado.

\section{O restante do quadro: A distribuição de ânforas no império romano ocidental}

A maior parte das novas informações acerca do comércio de azeite de oliva durante o período romano é proveniente de outras províncias, cujas descobertas complementam até certo ponto nossa percepção sobre as importações na Bretanha romana. Novos dados apareceram no que se refere à tipologia das ânforas, novos selos e tituli picti, melhores datações ou famílias de selos. Talvez a contribuição mais importante venha das áreas de produção das ânforas de azeite, no vale de Guadalquivir e no norte da África.

O vale do Guadalquivir tem fornecido nos últimos 20 anos descobertas de mais oficinas de ânforas associadas a uma série de tipologias, tais como a Dressel 20 e Dressel 23, mas também algumas variações, assim como novos selos. Berni (2008) publicou uma síntese de todos os vasos de azeite de oliva produzidos no vale do Guadalquivir em mais de 100 manufaturas de ânforas, explicando as relações entre os selos. Ele definiu o conceito de famílias de selos, que inclui variações de selos provenientes de um mesmo centro produtor que provavelmente indicam uma cronologia diferente. A associação de selos proposta tornou mais simples identificar as origens de alguns selos desconhecidos, e nos permitiu uma melhor datação de alguns deles. 
No que se refere ao norte da África, o trabalho de Bonifay (2004) aperfeiçoou nosso conhecimento sobre tipologias de ânforas locais, suas origens e produção na região norte africana, assim como o conteúdo exato de cada formato. Isto significa que algumas das ânforas norte africanas atribuídas ao comércio de azeite de oliva na verdade não são recipientes deste produto, mas sim de vinho ou molho de peixe. Ainda que o número e porcentagem de vasilhas norte africanas ainda sejam relativamente baixos as novas informações modificam algumas das noções prévias.

Finalmente, as escavações do Monte Testatio (Roma) (Blázquez e Remensal, 2010; 2014) complementam a documentação sobre a importação de azeite de oliva uma vez que este grande local de descarte de ânforas registra selos e tituli picti associados a ânforas Béticas e Africanas. Atualmente, é especialmente importante para os contextos do final do século II d.C. e século III d.C. a datação e associação de selos com manufaturas específicas. Independentemente das publicações, novos dados sobre o Monte Testatio podem ser acessados na base de dados do CEIPAC (http://ceipac.ub.edu).

Todas estes novos dados modificam algumas estatísticas do trabalho inicial de Carreras e Funari (1998) em aspectos relacionados à epigrafia em Dressel 20, tais como catalogação, datação, origem e regiões de produção. Estas mudanças não são relevantes no que se refere à distribuição interna de azeite de oliva na província, mas elas podem ser relevantes em termos de cronologia e comércio regional.

Porém, outros estudos semelhantes com quantificação de ânforas e publicação de selos e tituli picti em sítios continentais complementam a distribuição da Bretanha romana. Eles nos oferecem um caminho para deduzir uma possível rota pela qual estes produtos chegavam às ilhas britânicas. Por exemplo, a figura 7 ilustra uma maior densidade de ânforas Dressel 20 em mais de 200 sítios nas províncias da Germania, Gallia e Britannia. 


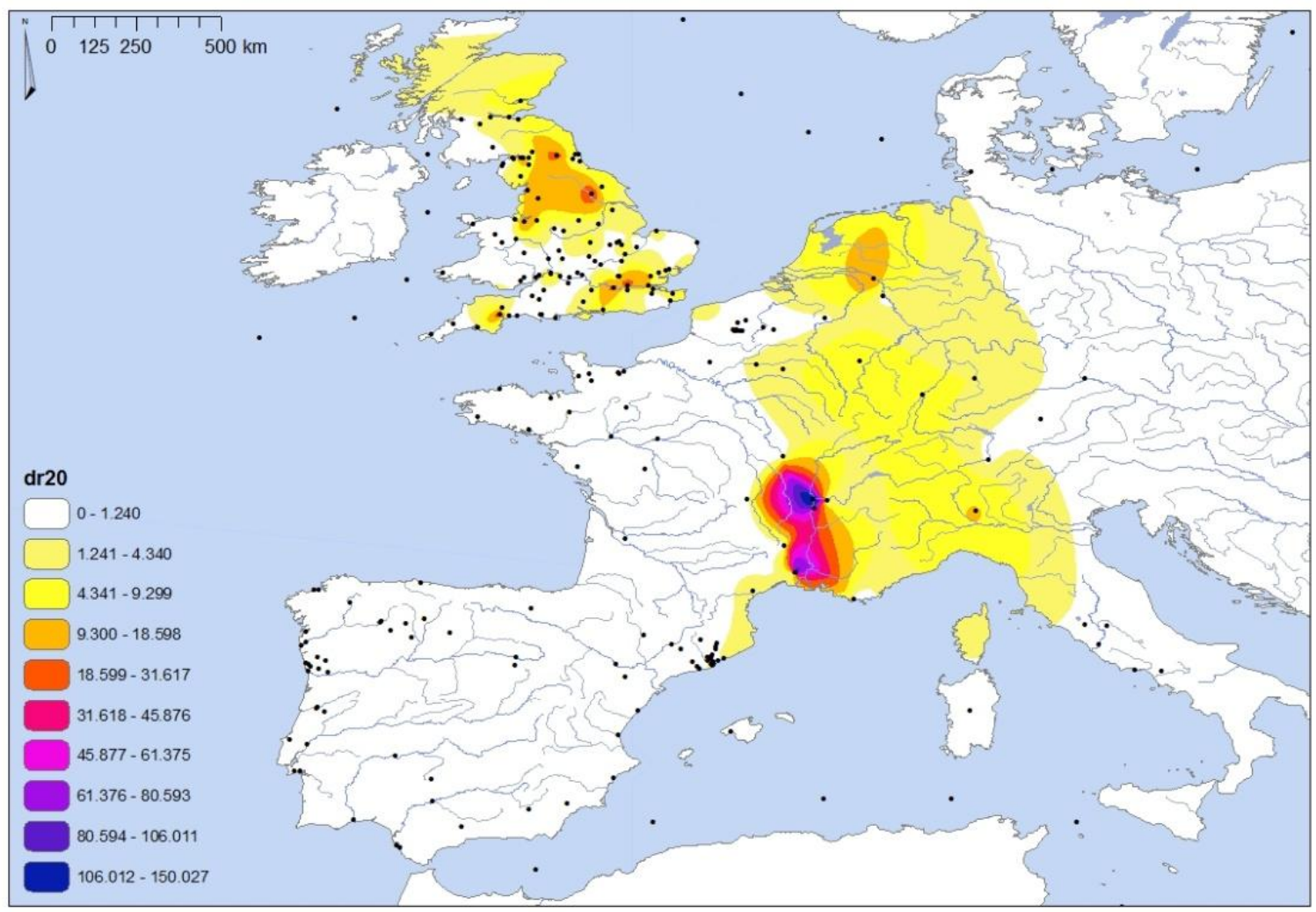

Fig. 7. Distribuição da densidade de ânforas Dressel $20(\mathrm{cg} / \mathrm{m} 2)$ no Império Romano Ocidental

Concentrações de Dressel 20 são registradas no Vale do Reno e em centros consumidores como os sítios militares romanos no limes germânico e britânico. A visão geral do Império Romano Ocidental confirma que aquelas ânforas Béticas de Azeite de oliva foram alocadas em destinações militares como parte de um complexo sistema publico de redistribuição. Claramente, o mapa ainda é cheio de lacunas devido à falta de pesquisas e quantificação precisa das ânforas e sua epigrafia associada.

Felizmente, o panorama está mudando gradualmente com novos estudos arqueológicos regionais que estão suprimindo estas lacunas em territórios como o norte da Gália. Laubenheimer e Marliere (2010), por exemplo, publicaram um livro sobre as ânforas do Noroeste da Gália, uma região entre a Germania inferior e a Britannia, a qual mostra os mesmos tipos de ânforas, mas em menor quantidade. Da mesma forma, a região De Franche-Comté é também um território cujas evidências anfóricas estão sob estudo, e com sorte os resultados serão publicados em breve.

No que se refere a Germania Inferior, uma visão geral das importações espanholas no início do Principado pode ser obtida a partir do trabalho 
de González Cesteros (2014), que aponta uma importante presença de ânforas béticas de azeite de oliva na maioria dos campos militares, mas os dados foram quantificados de uma forma que dificulta a comparação com outros sítios e regiões. No entanto, o seu trabalho é interessante no que se refere a tipologias iniciais de ânforas de azeite de oliva Bético anteriores a Dressel 20, com modelos como a Obedaren 83 e Haltern 71, em campos como os de Oberaden, Haltere ou Anreppen.

A curta ocupação de alguns campos militares em ambos os lados do rio Reno contribuem para uma grande precisão nos dados sobre como o comércio de azeite de oliva iniciou-se na Germania Inferior. Por exemplo, o sitio de Novaesium (Neuss) registra ao menos 7 campos militares de madeira datados com precisão de 16 a.C. até 43 d.C. Todas as ânforas foram classificadas e compiladas de acordo com o assentamento e o período aos quais pertenciam (Carreras e Berni, 2014), assim nós pudemos determinar quando tipologias específicas foram importadas pela primeira vez para o sítio.

Uma característica notável é que a Haltern 70 foi a primeira tipologia de ânfora Bética importada em grande quantidade em Naus, e posteriormente os modelos Oberaden 83 e Haltern 71, que são as predecessoras da Dressel 20. A Oberaden 83 surge no primeiro assentamento militar (16-12 a.C.) e evolui para a Haltern 71 e posteriormente para a Dressel 20, que é a tipologia Bética mais importante no campo 7 (28-43 d.C.). Deve-se ter em mente que a Bretanha foi conquistada pelo imperador Cláudio em 43 d.C. , quando a versão Dressel 20 já era a ânfora padrão produzida no vale do Guadalquivir.

Porém, a Bretanha documenta poucos exemplares da Oberaden 83 (circa 20 a.C. -9 d. C.) datadas da ultima década antes de cristo, em um contexto pré-romano em Prae Wood e Gatesbury Track (Williams e Peacock, 1983). Assim sendo, existia um consumo atestado de azeite de oliva entre as comunidades da Idade do Ferro na Bretanha. A propósito, nenhuma evidência de Haltern 71 (circa 1d.C. - 40 d.C.) foi registrada até agora.

O recente estudo do assentamento militar de Kops Plateau (Nijmegen) (Carreras e van den Berg, 2017) também fornece testemunhos de importações primitivas de ânforas na Germania Inferior. O local foi ocupado entre 12 a.C. e 68/69 d.C., e também demonstra a evolução tipológica das ânforas béticas globulares de azeite da Oberaden 83 para a Haltern 71 e, finalmente, para a Dressel 20. A importância do consumo de azeite no sítio aumentou com o passar do tempo, sendo a Dressel 20 o modelo de ânfora mais importante no final do período. 

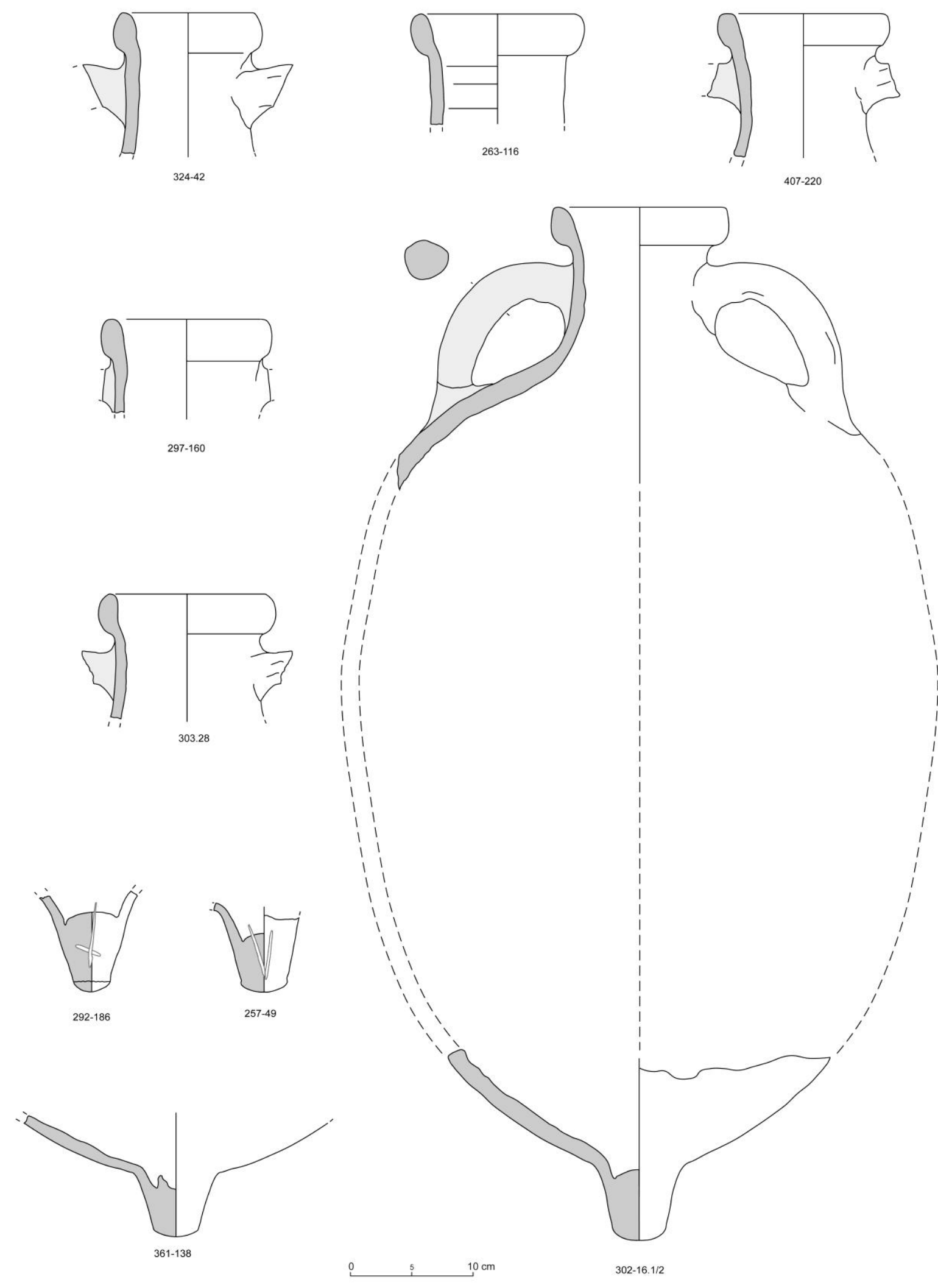

292-186

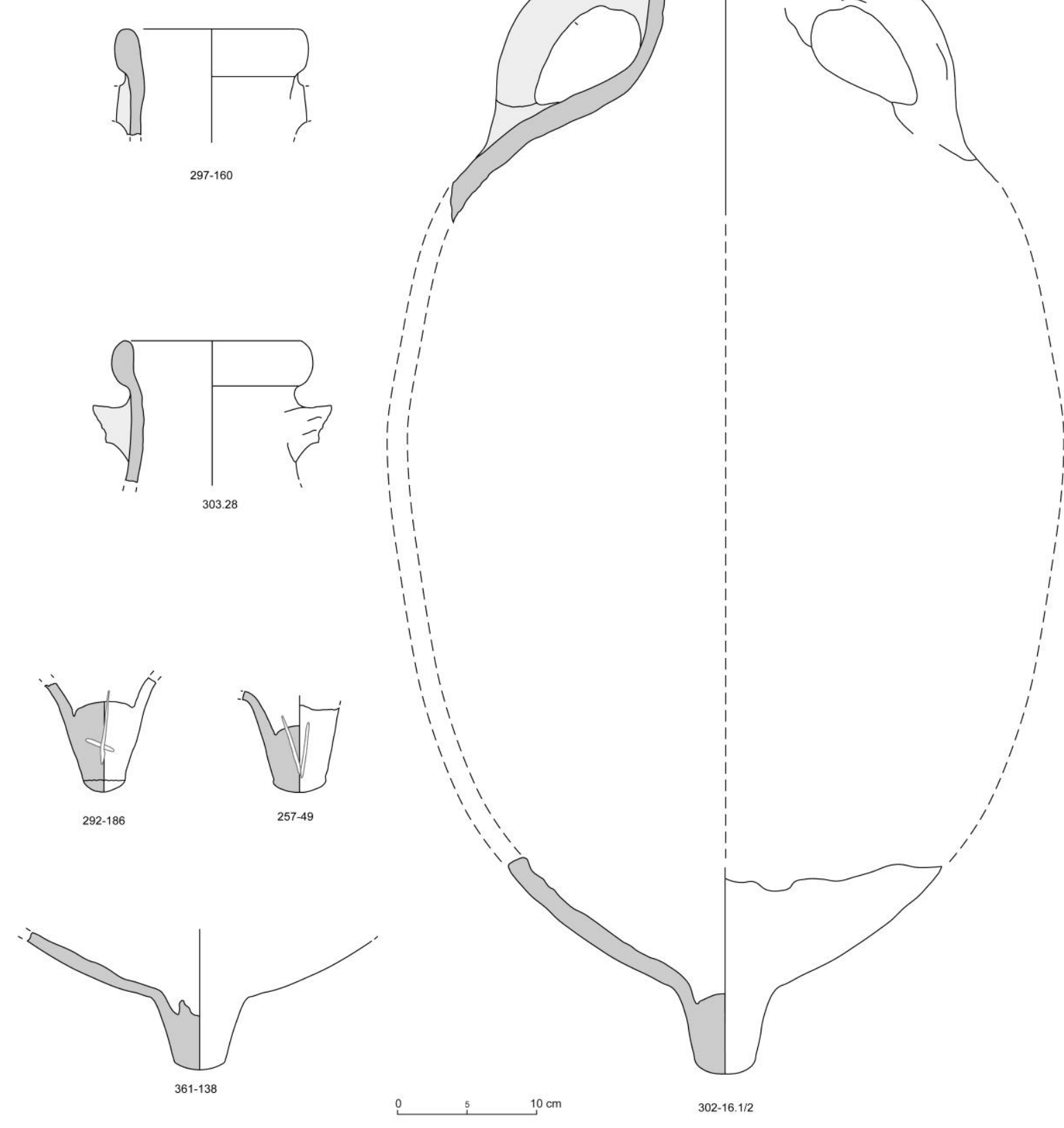

$257-49$
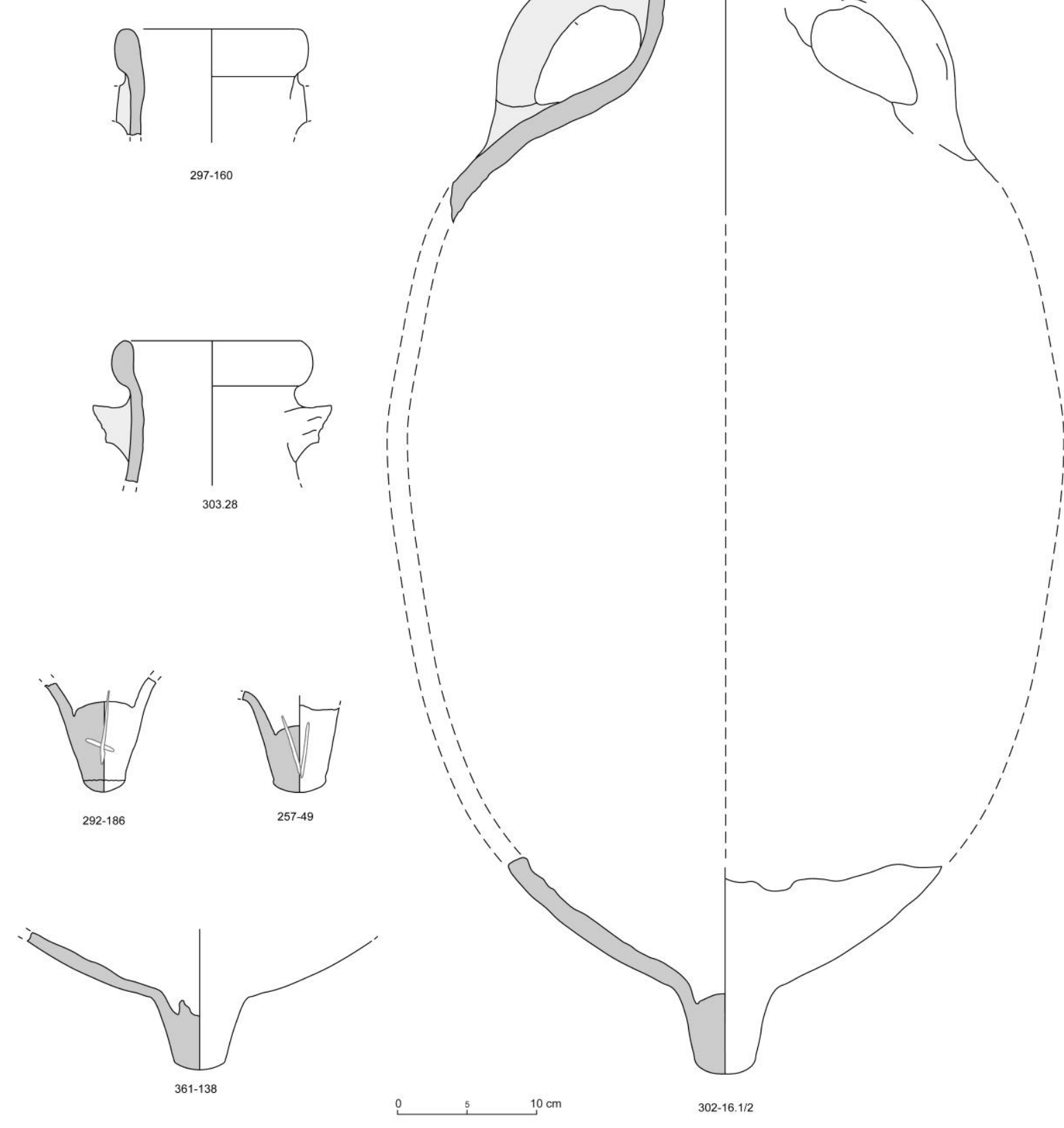

Fig. 8. Exemplos da Obarden 83 provenientes de Kops Plateau ( Nijmegen) (Carreras and van der Berg, 2017: 52, fig, 4) 
Finalmente, os ainda não publicados estudos sobre as ânforas de Xanten constituem mais evidências da relevância do consumo do azeite de oliva entre militares do Limes Germânico. A maioria dos cenários em Xanten pertence ao século II d.C e documentam uma enorme presença da Dressel 20 Bética, assim como ocorre na Bretanha romana. Desta forma, as importações de ânforas Dressel $20 \mathrm{em}$ assentamentos militares apresentam um padrão similar nos limes destas províncias, o que reforça a ideia de um sistema público de distribuição. Embora o estudo ainda esteja inacabado, mais de 400 selos de ânforas foram encontrados em Xantem, tornando-a um dos principais mercados de azeite de oliva desta província.

Ainda que a distribuição da Dressel 20 aparente ser semelhante tanto na Bretanha quanto na Germânia, o mesmo não ocorre com os vasos norte africanos. Existem apenas alguns exemplares de ânforas Norte africanas nas províncias germânicas (i.e. Kops Plateau - Carreras e Van den Berg, 2017), mesmo em períodos tardios. Talvez as rotas comerciais no período tardio romano fossem diferentes e o caminho pelo Atlântico fosse a principal rota para as Ilhas Britânicas. Nos últimos anos vem se observando um novo interesse em pesquisar o oceano atlântico como uma rota comercial basilar entre diferentes províncias romanas (Carreras e Morais, 2012).

Apesar das dificuldades relacionadas à arqueologia subaquática no atlântico, sítios costeiros têm fornecido numerosos vestígios arqueológicos que relacionam centros de produção mediterrâneos com locais de consumo nortenhos. Independentemente dos diversos portos nas costas Lusitânica e Gálica que documentaram ânforas de azeite semelhantes àquelas encontradas em grande quantidade nos limes Britânicos e Germânicos, a recente publicação acerca da cerâmica de Vigo (Fernández, 2014) ao noroeste da Espanha acabou revelando-a como um importante centro de redistribuição tardio.

Vicus (Vigo) registra um grande número de ânforas norte africanas de verniz vermelho, assim como Vasilhas africanas e romano ocidentais tardias, que lembram o mesmo tipo de importação encontrado em períodos mais tardios no mar Irlandês e na Cornualha. No entanto, Vigo pode ter atuado como uma escala portuária compulsória na remessa para as terras do norte. Parte do escasso azeite de oliva norte africano transportado nestas latitudes era consumido aqui em seu caminho para os mercados do norte britânico. 


\section{Conclusões}

Como dito inicialmente, mais de vinte anos se passaram desde o lançamento do estudo pioneiro sobre a importação de azeite de oliva na Bretanha romana elaborado por Pedro Paulo de Abreu Funari. Não obstante a passagem do tempo e as pesquisas arqueológicas, a maior parte das conclusões apontadas naquele momento continuam válidas, uma vez que os novos dados não parecem contradizer as hipóteses anteriores. No entanto, a amostra de dados deve ser aperfeiçoada com novos materiais e atualizada com os mapas e estatísticas resultantes, com especial atenção para locais como Londres ou Vindolanda, onde houve importantes descobertas. No caso da Londres romana, a amostragem analisada vinte anos atrás não era grande o suficiente para uma cidade daquele tamanho. Assim sendo, qualquer avanço adicional demandará um estudo mais completo das muitas coleções de ânforas que ainda permanecem no Museu de Londres. Talvez esta seja uma das cidades da Grã-Bretanha que poderá oferecer surpresas futuras no que se refere ao volume e à variedade no consumo de azeite de oliva, sendo necessária pesquisa adicional. Além das cidades, alguns dos territórios estudados anteriormente não tinham dados suficientes, devido à falta de publicações sobre ânforas ou estudos diretos por pesquisadores. Desta forma, ainda existem algumas áreas em aberto que devem ser completadas com os dados disponíveis.

Como foi demonstrado neste artigo, o número de selos e tituli picti em ânforas Dressel 20 tem aumentado com as novas escavações, assim catálogos publicados vinte anos atrás já estão desatualizados. Provavelmente não existe um grande número de novos selos, mas a atualização e publicação constante são necessárias. Assim que estes catálogos e bases de dados forem completamente atualizados, será possível revisar novamente as conclusões apontadas pelas estatísticas e mapas do corpus prévio. A sensação é que teremos pequenas mudanças nestas conclusões, mas novos dados são demandados para justificar este argumento.

O azeite de oliva era um ingrediente exótico na culinária das Ilhas britânicas, mas não era o único. Estudos recentes sobre plantas exóticas revelam um padrão curiosamente similar na distribuição na província que merece uma explicação mais aprofundada em termos de custo, poder de compra, preferências étnicas ou mesmo simbolismo. Associar a distribuição de diferentes produtos com padrões semelhantes está nos levando, de fato, a identificar variações na composição social da população Romano-Bretã. Esta análise está em sua fase inicial e requer métodos complexos que podem relacionar diferentes tipos de dados. Um Heródoto, Unifesp, Guarulhos, v. 3, n. 1, Março, 2018. p.288-312 
destes novos métodos é a análise de DNA, que nos permite identificar diferentes populações na Bretanha romana, concentradas em diferentes regiões, períodos e cidades. Excelentes resultados iniciais foram obtidos no cemitério da Londres romana, onde foi documentada uma população bastante heterogênea vinda do mediterrâneo, norte da África e mesmo da China, e uma população local relativamente baixa. Estes novos dados podem auxiliar a análise de temas como a migração e questões étnicas durante o império romano, algo impossível anteriormente.

Um outro tópico é como estes produtos chegaram à província da Bretanha romana. Até o presente momento os modelos de transporte foram desenvolvidos para identificar as rotas mais adequadas, e então eles podem ser comparados com as ânforas registradas nos sítios ao longo destas rotas. Muitas regiões na Europa Ocidental são atualmente estudadas com metodologias similares em quantificação, as quais irão permitir uma visão mais aprofundada destas possíveis rotas. No longo prazo, dados sobre outras províncias romanas irão ajudar a entender os mecanismos do comércio de azeite de oliva na Bretanha romana.

Em suma, os estudos sobre a importação de azeite de oliva na Bretanha romana estão longe de acabar. Eles foram iniciados há quase vinte anos com um primeiro catálogo contendo todos os vestígios de ânforas (Vasos Béticos e Norte africanos, incluindo a sua epigrafia) com sua interpretação correspondente. Naquela época, uma serie de hipóteses foram apresentadas, as quais geraram novos questionamentos sobre padrões de consumo, assim como etnicidade, poder de compra ou simbolismo. As questões continuam abertas à análise com a inclusão de novos dados (plantas exóticas, cerâmica, DNA) que podem auxiliar a abordar nossas próprias questões.

\section{Referências}

ALCOCK, J. Food in Roman Britain. Oxford, 2001.

BERNI, P. Epigrafía anfórica de la Bética. Nuevas formas de análisis. Barcelona, 2008.

BLÁZQUEZ, J.M.; REMESAL, J. Estudios sobre el Monte Testaccio (vol. 5). Barcelona, 2010.

BLÁZQUEZ, J.M.; REMESAL, J. Estudios sobre el Monte Testaccio (vol. 6). Barcelona, 2014. 
BONIFAY, M. Etudes sur la ceramique romaine tardive d'Afrique. BAR Int.Ser. 1301, Oxford, 2004.

CALLENDER, M.H. Roman amphorae: with an index of stamps. London, 1965.

CARRERAS, C. "Los beneficiarii y la red de aprovisionamiento militar de Britannia e Hispania". Gerión 15, 1997, pp.151-176.

CARRERAS, C. Economía del imperio romano: la importación de alimentos. Barcelona, 2000.

CARreras, C.; Berni, P. "Hispanic Imports in the First Military Camps of Novaesium (Neuss): Lager 1-7 (Augustus-Flavians)". MBAH 32, 2014, pp.173-208

CARRERAS, C.; DE SOTO, P. "The Roman transport network: a precedent for the integration of European mobility". Historical Methods: A Journal of Quantitative and Interdisciplinary History vol.46.3, 2013, pp.117-133.

CARRERAS, C.; FUNARI, P.P.A. Britannia y el Mediterráneo: estudios sobre el abastecimiento de aceite bético y africano en Britannia. Barcelona, 1996.

CARRERAS, C.; MORAIS, R. "The Atlantic Roman trade during the Principate: new evidence from the Western façade". Oxford Archaeological Journal 31.4, 2012, pp.419-441.

CARreras, C.; VAn DEN BerG, J. Amphorae from the Kops Plateau (Nijmegen). Trade and supply to the Lower-Rhineland from the Augustan period to AD 69/79. Archaeopress Roman Archaeology 20, 2017, Oxford.

CARreraS, C.; Williams, D.F. "Spanish olive oil trade in late Roman Britain: Dressel 23 amphorae from Winchester". Journal of Roman Pottery Studies vol. 10, 2003, pp.64-68.

CoOL, H.E.M. Eating and drinking in Roman Britain. London, 2006.

EvANS, J.C. "Balancing the Scales: Romano-British Pottery in Early Late Antiquity". Late Antiquity Archaeology, volumen 10, issue 1, 2013,pp.425450 .

EvanS, J.C.; WilLIAMS, D.F. "The amphorae". In S.Sworn, H.Dalwood, C.J.Evans and E.Pearson (eds.) Archaeological excavation at the City Campus, University of Worcester. Wroxeter, 2014, pp.67-68. 
FERNÁNDEZ, A. El comercio tardoantiguo (s.IV-VII) en el Noroeste Peninsular a través del registro ceramic de la ría de Vigo. Roman and Late Antique Mediterranean Pottery 5, Archaeopress. Oxford, 2014.

FUNARI, P.P.A. Dressel 20 inscriptions from Britain and the consumption of Spanish olive oil: with a catalogue of stamps. BAR Tempus Reparatum, Oxford, 1996.

GONZÁlEZ CESTEROS, H. Ánforas hispanas en la Germania Inferior antes de la formación de la provincia 20 a.C. - 69 d.C.(Ump. Thesis),

UniversitatRoviraVirgili, 2014.

HOWELL, I. Roman and medieval development South of Cheapside. Excavations at Bow Bells House, City of London, 2005-6. Museum of London Archaeology, Archaeology Study Series 26, 2013, London.

JARRETT, K. (Ethnic, social, and cultural identity in Roman to post-Roman Southwest Britain. Sheffield, 2010.

Kelly, A.M. "The Discovery of Phocaean Red Slip Ware (PRSW) Form 3 and Bii ware (LR1 amphorae) on sites in Ireland - an analysis within a broader framework". Proceedings Of The Royal Irish Academy, 110 : 2010, $35-88$

LAUBENHEIMER, F.; MARLIERE, E.Échanges et vie économique dans le NordOuest des Gaules. Le témoignage des amphores du IIe siècle avant J.C au IVe siècle après J.C., Besançon, 2010.

LEACH, S.;ECKARDT, H. ;CHENERY, C. ; MULDNER, G. ; LEWIS, M. “A lady of York: migration, ethnicity and identity in Roman Britain". Antiquity 84 (323), 2010, pp.131-145.

LiVARDA, A.; ORENGO, H. "Reconstructing the Roman London flavourscape: New insights into the exotic plant trade using network and spatial analyses". Journal of Archaeological Science, 55, 2015, $244-252$.

MARLIERE, E.; TORRES, P. “Tonneaux et amphores à Vindolanda: contribution à la connaissance de l'approvisionnement des troupes stationnées sur le mur d'Hadrien (II)". In A.Birley and J.Blake (eds.) Vindolanda. The excavation of 2003/4. Vindolanda, 2005, pp.214-236.

ORENGO, H.; LIVARDA, A. “The seeds of commerce: A network analysisbased approach to the Romano-British transport system". Journal of Archaeological Science, 66, 2016, 21-35 
SHEEHAN-FINN, K. "Vindolanda's amphora stamps". Chesterholm Stone Project Vindolanda, 2012, pp.1-21.

SMITH, R.S. Suburban life in Roman Durnovaria. Additional Specialist report: Finds pottery. Dorchester, 2008.

SWAN, V.G. "Legio VI and its men: African legionaries in Britain". Journal of Roman Pottery Studies 5 : 1992,1-33.

SWAN, V.G. Ethnicity, conquest, and recruitment: two case studies from the Northern military provinces. Journal of Roman Archaeology (suppl. Series), Ann Arbor.

WiLliaMs, D.F. "Amphorae". In M.Jones and T.Jones (eds.) RomanoBritish settlement and cemetery. Mucking excavations. London, 2013, pp.152153.

WiLliAMS, D.F. "The Amphorae". In J.M.McComish (ed.) Roman, Anglian and Anglo-Scandinavian activity and medieval cemetery on land at the junction of Dixon Lane and George Street, York. York, 2015, pp.95-98.

WiLliamS, D.F.; CARRERAS, C. "North African amphorae in Roman Britain: a Re-appraisal". Britannia 26, 1995, pp.231-252.

Williams, D.F.; PEACOCK, D.P.S. "The importation of olive-oil into Roman Britain". En J.M.Blázquez and J.Remesal (eds) Producción y comercio de aceite de oliva en la Antigüedad. II Congreso,. Madrid, 1983, pp.263-280. 